\title{
QUIETAS E CALADAS: \\ as atividades de movimento com as crianças na Educação Infantil'
}

\author{
Dijnane Fernanda Vedovatto Iza* \\ Maria Aparecida Mello**
}

RESUMO: Este artigo discute as atividades de Movimento nas rotinas diárias de professoras de Educação Infantil, sob a perspectiva da teoria Histórico-Cultural de Vigotski, cuja concepção de desenvolvimento infantil prioriza a cultura e a atividade mediada de professores, como determinantes nas aprendizagens e no desenvolvimento infantis. As atividades de Movimento vão além do desenvolvimento motor, relacionando-se com resolução de problemas, questionamentos, criatividade, memória, atenção, abstração, etc. As professoras da creche investigada têm experiência de trabalho com as crianças, mas falta-lhes o conhecimento de como trabalhar atividades educativas com Movimento e, portanto, priorizam a manutenção das crianças em situação de Não-Movimento. Tais práticas de manter as crianças quietas e caladas revelam as concepções de criança e movimento das professoras, indicando a urgência de reformulação dos processos e cursos de formação inicial e continuada de professoras de Educação Infantil.

Palavras-Chave: Atividades de Movimento; Educação Infantil; Teoria Histórico-Cultural.

\section{QUIET AND SILENT: the movement activities with children in childhood education}

ABSTRACT: This article discusses the movement activities in everyday routines of the Basic Education teachers, under the perspective of Vigotski's' Historical-Cultural Theory, whose conception about childish development has a focus on the culture and teachers' mediated activities, as a determination for the childish learning and development. The Movement activities transcend the motor development. It is related to problems resolution, questions, creativity, memory, attention, abstraction, and so on. The Basic Education teachers investigated have experience on working with children, but they don't have knowledge about how to work with movement activities in the educational perspective and thus, they keep the children in a situation of non-movement. Those practices about how to maintain the children quiet and silent show the teachers' conceptions about child and movement, indicating the urgency of a reformulation on the initial and continual processes and courses of the Basic Education teachers. Keywords: Movement Activities; Early Childhood Education; Historical-Cultural Theory.

\footnotetext{
* Doutora em Educação pelo Programa de Pós-Graduação em Educação da Universidade Federal de São Carlos - UFSCar. Professora da Fundação Educacional São Carlos. Pesquisadora do Núcleo de Estudos e Pesquisas sobre a Escola de Vigotsky - NEEVY. E-mail: dijnane@ig.com.br

* Professora do Programa de Pós-Graduação em Educação e do Departamento de Metodologia de Ensino da UFSCar. Coordenadora do Núcleo de Estudos e Pesquisas sobre a Escola de Vigotsky -NEEVY - CNPq. E-mails: mmello@ufscar.br e mare@terra.com.br
} 


\section{INTRODUCุÃO}

A história da origem das creches, associada ao longo tempo de permanência junto à promoção social, cristalizou, por muito tempo, uma visão de exclusividade do "cuidar" no trabalho das professoras de crianças pequenas, em detrimento de uma intencionalidade educacional de qualidade, que envolvesse, por exemplo, o desenvolvimento da autonomia na criança. $\mathrm{Na}$ mesma proporção, a maioria das profissionais que trabalhava com as crianças pequenas não tinha formação docente e ainda havia casos de pessoas analfabetas. Em decorrência desse quadro, o trabalho dessas mulheres foi, e ainda hoje continua a ser, pouco valorizado, uma vez que é associado à classe trabalhadora e de baixa renda. Além disso, a maioria dos salários, bem como as condições de trabalho dessas mulheres, têm sido insuficientes para o desenvolvimento de atividades que pressuponham o cuidado e educação de qualidade para crianças de 0 a 3 anos.

A partir da LDB (1996), a educação é um direito de todas as crianças de 0 a 6 anos, e não apenas daquelas cujas mães trabalham fora de casa. As creches passaram a pertencer à Secretaria Municipal de Educação e Cultura e, com isso, é evidenciada a preocupação em desenvolver um trabalho educativo associado aos cuidados de que as crianças pequenas necessitam. Essa mudança facilitou uma parceria entre a Secretaria Municipal de Educação e Cultura de São Carlos, o Departamento de Metodologia de Ensino da Universidade Federal de São Carlos e o Departamento de Arquitetura e Urbanismo da Escola de Engenharia de São Carlos da USP, com a finalidade de desenvolver um diagnóstico das creches da cidade, de forma a levantar as condições pedagógicas, de pessoal, de estrutura física, demanda para creches, entre outros, visando a propor melhorias para a qualidade das instituições de Educação Infantil.

O presente trabalho é parte desse projeto, intitulado "Diagnóstico das creches do Município de São Carlos" (1999), cujo objetivo principal foi subsidiar o desenvolvimento de políticas públicas para a Educação Infantil, por intermédio da construção de uma parceria com o setor público, que facilitasse a implementação das decisões estabelecidas pela equipe formada por professores de duas universidades e de dirigentes municipais. 
Um dos principais problemas na Educação Infantil é a exacerbação da escolarização da criança que reflete uma imposição de posturas e movimentos aos seus corpos, impedindo-as de brincar, que é a atividade mais importante nessa faixa etária, pois, por meio dela, a criança aprende e se desenvolve.

Daí a necessidade de realizarmos uma pesquisa que tivesse como foco as atividades de movimento das crianças na Educação Infantil e os tipos de mediações das professoras para proporcionar ou não essas atividades. Nesse contexto, surgiram algumas questões que fundamentaram este trabalho, são elas: em que momentos da rotina diária da creche ocorrem atividades de movimento? Que atividades de movimento as crianças realizam espontaneamente (atividade livre)? Que atividades de movimento são propostas pelas professoras (atividade dirigida)? Como essas atividades são propostas? $\mathrm{Na}$ rotina diária da creche, quais oportunidades são oferecidas às crianças para se movimentar? As crianças têm acesso a espaços diferentes e a materiais diversificados?

Para investigar tais questões, utilizamos como referencial teórico a abordagem Histórico-Cultural defendida por Vigotski, que trabalha o desenvolvimento humano na perspectiva da cultura e das atividades mediadas entre os indivíduos, destacando a importância do papel do professor como mediador das aprendizagens e do desenvolvimento infantis.

\section{O DESENVOLVIMENTO DA CRIANÇA NA PERSPECTIVA HISTÓRICO-CULTURAL}

A criança, desde o nascimento, é cercada de experiências sociais, inicialmente com os familiares, depois com adultos "estranhos", com outras crianças e, na medida em que ela interage com o mundo que a cerca, apreende como é o seu funcionamento, compreende os comportamentos que caracterizam a sociedade em que vive.

Nesse sentido, as profissionais da Educação Infantil são de extrema importância no processo de desenvolvimento das crianças e na qualidade das relações estabelecidas com elas. A criança vai apreendendo as ações práticas, essenciais para atuar na sociedade. As "ações de orientação" preparam as "ações práticas", de maneira que, diante de determinado problema, a criança avalia a situação articulando "ações 
internas” para responder ao que lhe é apresentado. “(...) A criança assimila novas ações internas, psíquicas, que lhe permitem resolver problemas cada vez mais complexos e variados" (MUKHINA, 1996, p. 46).

Portanto, é imprescindível que a professora conheça e considere o desenvolvimento da criança para que possa auxiliá-la a apropriar-se de situações mais complexas a cada dia. No entanto, o ensino deve guiar o desenvolvimento da criança sem prender-se exclusivamente a ele, ou seja, as atividades propostas à criança devem ajudá-la a desenvolver novas habilidades. Na perspectiva histórico-cultural, significa a professora trabalhar na zona de desenvolvimento próximo ${ }^{2}$ da criança, que é o aprender algo novo em função da colaboração de alguém, mas esse aprender está diretamente ligado às possibilidades da criança para aprender.

Vigotski (2001) alerta que trabalhar na zona de desenvolvimento próximo da criança é mais importante do que no nível de desenvolvimento atual, que significa aquilo que a criança já aprendeu, pois a colaboração da professora na atividade que a criança ainda não consegue resolver sozinha contribui para que ela mobilize os seus conhecimentos, já efetivos, para apropriar-se de novos.

Quando recebe ajuda de outra pessoa, a criança amplia seu aprendizado, mas é importante considerar suas possibilidades, pois ela aprende com maior facilidade quando as tarefas exigidas estão mais próximas do que consegue fazer. Assim, a aprendizagem está sempre à frente do desenvolvimento, uma vez que provoca o desenvolvimento que se encontrava na "zona de desenvolvimento próximo". O educador tem de reconhecer essas possibilidades de aprendizagem da criança para auxiliá-la na apropriação dos conhecimentos. Por exemplo: com o passar do tempo, a criança aprende a sustentar a cabeça, a sentar, engatinhar, andar, enfim adquire conhecimento das formas de comportamento do ser humano. Mas isso só é alcançado porque há a contribuição do adulto, que a incentiva a realizar esses movimentos (MUKHINA, 1996). Estimular a criança a deslocar-se, oferecer-lhe os objetos, instigar-lhe a curiosidade e o interesse em explorar o que o adulto lhe apresenta são exemplos de ações simples que impulsionam as aprendizagens e o desenvolvimento da criança.

Essas ações podem ser entendidas como "mediações" que o adulto estabelece nas relações com a criança. Mello (2001, p. 25-26) esclarece esse conceito da seguinte forma: 
O Homem apropria-se de conhecimentos pela via das mediações, as quais podem ser infinitas. Essas mediações modificam-se à medida que o indivíduo se desenvolve e cria novas necessidades para si (...). Durante a sua vida o homem, assimila as experiências produzidas socialmente por intermédio da aquisição de significados. A significação exerce, assim, a função de mediadora na assimilação da experiência humana pelo homem. A apropriação destes significados dependerá do sentido subjetivo que cada indivíduo imprime a eles, sentido esse que se cria na vida e na atividade social desse indivíduo. (MELLO, 2001, p. 25-26)

Portanto, a criança apreende o mundo por meio das mediações dos adultos, dos objetos e das outras crianças e, nesse processo, os movimentos que executa nas atividades são fundamentais para o seu desenvolvimento. Assim, é necessário que a professora coloque à disposição da criança diversos materiais, possibilite interações com outras crianças e esteja atenta aos movimentos, pois a criança adquire inúmeros conhecimentos explorando não apenas o próprio corpo, mas também o ambiente e os objetos que a cercam. A manipulação desses objetos possibilita apreender seus significados, por exemplo, o copo é um recipiente para beber ou a colher é um instrumento para levar comida à boca. Embora tais objetos possam ser usados para outras coisas, a criança sabe para quê serve o copo ou a colher, que são utilizados de determinada maneira, e isso faz parte das regras do comportamento social. Dessa forma, ao conhecer a utilização dos objetos, ela está compreendendo as regras sociais.

Essas experiências sociais que a criança vivencia proporcionam a compreensão do funcionamento da sociedade, que será, mais tarde, no terceiro ano de vida, reproduzida por meio de jogos dramáticos, que nascem para satisfazer a necessidade de convivência social das crianças com os adultos.

A criança representa as ações dos adultos, reproduzindo as regras dos comportamentos sociais, e, como complemento do jogo dramático, utiliza os objetos, atribuindo-lhes significados diferentes do seu uso social para representar suas ideias na brincadeira. "Dessa forma, um bloco de madeira, um carretel ou uma pedra podem servir de sabão para lavar a boneca" (MUKHINA, 1996, p. 116).

Inicialmente, a criança utiliza o objeto no jogo dramático chamando-o pelo nome verdadeiro. Em um segundo momento, ela chama o objeto de acordo com o papel que ele desempenha no jogo. Para 
Mukhina (1996, grifo da autora, p. 117): “A criança na primeira infância age inicialmente com o objeto e mais tarde compreende o significado do objeto no jogo".

Para a representação dos papeis sociais no jogo dramático, a criança articula, entre outras coisas, a linguagem e os movimentos. Assim, Galvão (2000) expõe:

Na infância é ainda mais pronunciado o papel do movimento na percepção. A criança reage corporalmente aos estímulos exteriores, adotando posturas ou expressões isto é, atitudes, de acordo com as sensações experimentadas em cada situação. (GALVÃO, 2000, p. 72)

A criança representa, em suas brincadeiras, as vivências e interações com os adultos por meio de gestos e posturas em uma situação imaginária, por exemplo: ao imitar o adulto fazendo bolo, substitui o bolo "verdadeiro" por algum outro objeto, faz o gesto de abrir o forno, colocar o bolo e fechar a tampa, gesticula, abrindo novamente o forno para retirálo, espera que esfrie, assoprando para comê-lo. Há todo um ritual de movimentos, gestos, posturas, condutas, palavras que simbolizam essa situação. Essa gama de movimentos experimentados por intermédio da brincadeira contribui para o desenvolvimento da criança.

\section{AS ATIVIDADES DE MOVIMENTO NA EDUCAÇÃO INFANTIL}

Concebemos o Movimento como uma ação educativa utilizada pelas professoras que realizam a mediação entre o conhecimento e a criança. Nesta perspectiva, o Movimento é intencional, abrangendo e enfatizando as relações e os valores sociais.

O Movimento aqui explicitado não é apenas motor, mas se relaciona com atividades de resolução de problemas, questionamentos, criatividade, compreensão, atenção, memória, abstração, entre outras habilidades importantes para a vida da criança.

Para que tais valores sejam trabalhados com elas, é necessário que o profissional tenha clareza do seu trabalho. $\mathrm{Na}$ atividade de pular corda, por exemplo, a criança pode ser instigada a vários questionamentos e valores, como: em que momento deve pular a corda, compreender o movimento da corda em relação ao corpo, tomar consciência de que pode obter sucesso ou não na atividade, respeitar o erro ou o acerto do colega, 
compreender que, na vida, podemos ter vitórias e derrotas, respeitar honestamente as regras inerentes à atividade, enfim essas são algumas, entre muitas, questões importantes a serem trabalhadas com a criança pequena e que não estão restritas ao aspecto de movimentar o corpo, no sentido estrito do ato motor (MELLO, 2001).

No desenvolvimento de atividades de Movimento para crianças de 0 a 6 anos, deve-se levar em consideração que elas são seres inteiros, não podem se limitar apenas a padrões motores preestabelecidos. Ao considerar apenas o aspecto motor, o desenvolvimento da criança pode ser limitado. $\mathrm{O}$ trabalho com atividades de Movimento pode ser ampliado de maneira a não desconsiderar o aspecto motor, mas também não se restringir a ele.

Cabe ao educador proporcionar à criança grande variedade de atividades, de modo que ela possa vivenciar diferentes situações, com materiais diversos, espaços diferenciados, etc., mas é importante salientar que não basta apenas a diversidade das atividades, dos materiais ou dos espaços, é essencial que a qualidade das relações entre crianças e adultos seja harmoniosa.

A mediação das professoras no desenvolvimento das atividades de Movimento na Educação Infantil é de extrema importância e por isso devem ser planejadas, visando ao desenvolvimento das crianças pequenas, de maneira que tragam efetivamente benefícios à vida destas em sociedade.

Ao propor atividades de Movimento, não as defendemos de forma isolada, mas afirmamos a importância que têm no trabalho com as crianças pequenas. Não vemos a atividade física apenas como promotora de atividades que visam ao desenvolvimento motor. Ela pode e vai, além disso, alcançando amplitude maior, a fim de proporcionar às crianças questionamentos e valores sobre a sociedade na qual estão inseridas, e isso depende, em grande parte, da mediação que o adulto exerce com elas.

É importante que a professora tenha muita criatividade para atender às motivações das crianças que são muito dinâmicas e desejosas de brincadeiras e jogos variados. Mais do que apenas apresentar as atividades, é interessante que o adulto coloque para elas situações nas quais sejam incitadas a resolver problemas durante a execução dos movimentos, apropriando-se, da melhor maneira, para realizar as atividades. É importante sempre respeitar o ritmo e a descoberta individual de cada criança. 
O aprendizado, desse modo, torna-se significativo na medida em que a criança explora as possibilidades de raciocínio, movimentos, controle motor, enfim, todos os aspectos coordenados de que ela necessita para resolver a situação em questão.

Direcionar os movimentos das crianças, tentando aperfeiçoá-los, pode ser um trabalho perdido, por tais movimentos não terem sentidos para elas, que vão executá-los mecanicamente e, assim, dificilmente serão apreendidos. Ao contrário, o aspecto lúdico e a contextualização das atividades são fundamentais para que a criança lhes atribua algum sentido. Para isso, a professora pode utilizar histórias, músicas, desenhos, etc.

Sob essa perspectiva, as atividades de Movimento podem desenvolver as habilidades de lateralidade, equilíbrio, noções de espaço e tempo, dentro e fora, esquema corporal, tônus muscular, enfim, uma infinidade delas que podem ser exploradas de inúmeras formas, abordando aspectos como alto/baixo, espaço e tempo, ritmo, forte e fraco, lento e rápido, entre outros. Em atividades como brincadeiras, jogos, danças, dramatizações e, ainda, por meio de diversos materiais, tais como: cordas, arcos, bolas, pneus, etc.

A importância do/a educador/a como mediador(a) no processo de desenvolvimento das crianças é incontestável, por isso há a necessidade de ter conhecimentos claros e específicos para a realização do trabalho educativo intencional junto às crianças pequenas (MELLO, 2001).

Essa mediação acontece diariamente com as crianças pequenas, assim, tendo como pressuposto que esta fase da vida é de fundamental importância para a aquisição de diferentes aprendizagens, o objetivo deste trabalho foi: identificar atividades de Movimento e de Não-Movimento desenvolvidas com as crianças na instituição pesquisada; saber como elas são realizadas, quem as desenvolve e em que momento da rotina diária da creche elas ocorrem.

\section{PROCEDIMENTOS METODOLÓGICOS}

Foi desenvolvido um protocolo de observação das atividades da rotina diária da creche pesquisada para investigar como as atividades de Movimento eram trabalhadas com as crianças de 0 a 6 anos. Para isso, utilizamos a abordagem Histórico-Cultural, cujo pressuposto é a mediação realizada pela professora com as crianças. 
Foram utilizadas videogravações efetuadas nos períodos da manhã e da tarde, três vezes por semana, durante dois meses, em diferentes horários, situações e faixas etárias das crianças, de maneira que pudessem garantir grande variedade de informações.

As filmagens referem-se a oito pajens/professoras responsáveis pelas seguintes faixas: 0 a 2 anos (berçário), 2 a 3 anos (infantil I), 4, 5 e 6 anos (infantil II). No total, foram gravadas doze fitas de vídeo de trinta minutos.

A creche pesquisada foi criada na década de $1980^{3}$ e atende o total de $122^{4}$ crianças: 62 em período integral e 60 em meio período, sendo que 57 têm idade de 4 a 6 anos e permanecem o período vespertino na Escola Municipal de Educação Infantil (EMEI) e, o outro período, nessa creche. São nove educadoras distribuídas da seguinte forma: três profissionais para o berçário, três para o grupo de crianças de 2 a 3 anos (infantil I) e três para o grupo de 4, 5 e 6 anos (infantil II), sendo uma professora para cada faixa etária.

Para organizar os dados gravados em doze fitas de vídeo, foi necessário assistir às videogravações, identificando as atividades desenvolvidas pelas professoras, tais como: alimentação, descanso, atividade dirigida, etc.

Assim, foi elaborado um protocolo para as filmagens, no qual foram registrados aspectos relativos à organização da creche. Para tal, consideramos os seguintes aspectos: tipo de atividade desenvolvida, tempo de duração da atividade, espaço utilizado, sequência dos acontecimentos em que a professora realizou a atividade e envolvimento das crianças, além de ações que retratam como a professora desenvolveu a atividade e organizou o espaço. Esses elementos nortearam a análise das fitas de vídeo.

$\mathrm{Na}$ rotina diária, o foco central de investigação deste trabalho foi discutir o desenvolvimento das atividades de Movimento e de limitação do Movimento, que chamamos de Não-Movimento, promovidas pelas professoras para as crianças pequenas. Assim identificaram-se, nos protocolos, as informações sobre Movimento e Não-Movimento na rotina da creche. 


\section{MOVIMENTO E NÃO-MOVIMENTO NA CRECHE}

As professoras têm trabalho durante todo o tempo em que permanecem na creche e isso se refere exclusivamente a alimentar, garantir a higiene (banho, troca) e o descanso das crianças. Embora essas questões sejam relevantes e de extrema importância para o bem-estar das crianças, as professoras não oferecem outras atividades e isso, provavelmente, se deve à falta de organização do tempo de que dispõem.

Algumas professoras comentaram que havia um número excessivo de crianças e que se sentiam muito sobrecarregadas. No entanto, ao analisar o número de crianças na creche, temos: 4 meses a 2 anos - 20 crianças/3professoras; 2 a 4 anos - 55 crianças / 4 professoras; 4 anos - 25 crianças/1 professora; 5 anos -25 crianças/1 professora; 6 anos - 19 crianças/1 professora. Podemos perceber que não há número além daquele recomendado pelo documento "Subsídios para Credenciamento e Funcionamento de Instituições de Educação Infantil" (BRASIL,1998) ${ }^{5}$ :

Os parâmetros para a organização de grupos decorrerão das especificidades da proposta pedagógica, recomendada a seguinte relação professor/criança (p. 36): crianças de 0 a 1 ano - 06 crianças/ 01 professor; crianças de 1 a 2 anos - 08 crianças/01 professor; crianças de 2 a 3 anos - 12 a 15 crianças/01 professor; crianças de 3 a 6 anos - 20 a 25 crianças/01 professor.

Assim, o que parece ser evidente é a necessidade de outra organização que seja mais eficiente no atendimento às crianças, organização que leve em consideração a melhor qualidade do trabalho das profissionais, tanto nas condições de trabalho quanto no atendimento às crianças pequenas.

\section{ATIVIDADES DE MOVIMENTO}

As atividades sistematizadas de Movimento que estamos considerando aqui são as promovidas pelas professoras com a intenção de trabalhar Movimento com as crianças, tais como brincadeiras dirigidas, danças, dramatização, etc. Essa intencionalidade pressupõe a sistematização das atividades, cujos conteúdos privilegiem elementos que 
contribuam para o desenvolvimento da criança, como, por exemplo, lateralidade, equilíbrio, coordenação motora, noções de espaço e tempo, noções sobre a imagem do corpo, da expressão corporal, de controle tônico, entre outros. Além da intencionalidade e da sistematização das atividades, é imprescindível levar em consideração as peculiaridades das crianças pequenas, abordando esses elementos de forma lúdica.

Para selecionar os episódios de Movimento, utilizamos como critério os momentos em que as professoras demonstravam a intenção de promover atividades com Movimentos. A seguir, apresentamos e analisamos os dados com episódios da rotina da creche que indicam essas atividades.

Movimentos das crianças em função da música (crianças de 2 a 3 anos).

Depois do almoço, as professoras levaram as crianças em uma sala e colocaram uma música. Tentaram desenvolver uma atividade de roda com elas, mas algumas não se interessaram e foram mexer no rádio. A professora saiu da roda para tirar as crianças de perto dele, quando retornou, a atividade não teve continuidade, pois as crianças estavam dispersas com os brinquedos, a bola e a música que tocava na sala.

Algumas fizeram uma roda, sozinhas, na qual cantavam e dançavam, realizavam movimentos diversos, girando, andando, correndo, saltando, dançando, marchando, batendo palmas, etc. As professoras ficavam tirando as crianças que estavam mexendo ou querendo mexer no rádio.

É possível perceber, no episódio relatado, que a música incentivou as crianças a se organizarem e realizarem uma roda, sem a orientação da professora, talvez com base em experiências anteriores, nas quais as músicas eram trabalhadas em roda. Esse tipo de atividade livre é importante para as crianças, entretanto, precisa ser mesclada, no plano de aula, com atividades mais intencionais, nas quais a professora pode utilizar a música para ajudar a criança a desenvolver movimentos e habilidades que ainda não estão desenvolvidos. É interessante notar que a professora não se preocupou em desenvolver a atividade, mas sim em proteger o rádio.

$\mathrm{O}$ fato de as professoras não utilizarem estratégias que instigassem nas crianças a motivação para realizar a atividade de roda resultou na desistência da atividade. As crianças perderam, portanto, a oportunidade de explorar melhor os movimentos, desenvolver outras habilidades, fazer relações entre objetos, pessoas, acontecimentos, etc. A falta dessas estratégias as limitou a realizarem movimentos já conhecidos.

$\mathrm{Na}$ rotina para as crianças de 4 meses a 2 anos, não houve nenhuma atividade de Movimento promovida de maneira sistemática 
pelas professoras, ou seja, as crianças se movimentavam espontaneamente, sem mediação. As professoras utilizavam a maior parte do tempo cumprindo a rotina de cuidados com a higiene e alimentação das crianças, o que talvez as impedisse de otimizar o tempo e as atividades. Ofereciam brinquedos que ficavam guardados em cima do armário, em determinado momento da rotina, mas não procuravam desenvolver nenhum trabalho com eles.

A ênfase nas atividades de cuidado, sempre realizadas pelas professoras, não incentiva nas crianças práticas mais autônomas, principalmente, nas mais velhas e que já podem ser estimuladas a comer sozinhas, tomar banho, etc., com a supervisão da professora. Além disso, a falta de acesso aos brinquedos as impede de desenvolver habilidades de escolha, de iniciativa, entre outras.

A criança de 4 meses tem movimentos que expressam o que ela sente, pois é a maneira que tem de se comunicar, já que ainda não domina a fala. Esses movimentos espontâneos podem ser ampliados pela professora ao auxiliar o bebê a segurar objetos, direcionar sua atenção para diferentes objetos, fazendo-lhe massagens no corpo ao mesmo tempo em que conversa sobre os movimentos que está realizando, entre outros procedimentos de interação que são fundamentais para a criança aprender a dissociar seus movimentos e estabelecer vínculos com os adultos.

Outro aspecto a destacar para essa faixa etária é o grande intervalo de idade entre as crianças em uma mesma sala na creche. As crianças de 1 a 2 anos têm necessidades de movimento diferenciadas das crianças menores. Talvez esse modo de organizar as salas com as crianças dificulte a organização do trabalho das professoras, na perspectiva de relacionar o cuidado e a educação.

Com as crianças maiores aparece a tentativa das professoras de trabalhar as atividades de movimento de forma intencional, conforme o episódio:

Corre Cutia (crianças de 2 a 3 anos)

A professora pediu que todas as crianças se sentassem em roda e perguntou quem sabia brincar de corre cutia. Em seguida, comecou a caminhar em volta da roda, cantando a música "corre cutia na casa da tia, corre cipó na casa da vó, chupa cana com um dente só". Algumas crianças começaram a correr atrás da professora, quando outra professora interveio, dizendo que era apenas uma criança que deveria correr. A atividade não teve continuidade. 
Nessa atividade, as crianças não entenderam a brincadeira, uma vez que as professoras não a ensinaram. As crianças observavam as professoras, meio apáticas, sem motivação pela atividade. Embora essas professoras tenham tido a boa intenção de desenvolver alguma atividade, não obtiveram êxito, provavelmente em função de não a terem adequado às possibilidades das crianças naquele momento.

A dificuldade das profissionais em relação às atividades de Movimento é recorrente, pois algumas têm formação que não as incluem e outras nem têm a formação inicial do magistério.

É importante que a criança seja incentivada a realizar movimentos diversos e cabe à professora, como mediadora no processo educativo, ajudá-la a apreender novos conhecimentos.

\section{ATIVIDADES DE NÃO-MOVIMENTO}

As atividades de Não-Movimento a que nos referimos não significam a falta de movimento ou ficar sem se mexer, mas, sim, situações em que as crianças se encontram em limitação de movimentos imposta pelo tipo de atividade que as professoras propõem. Apesar dessa restrição, as crianças extrapolam e criam outras maneiras de se movimentar naquela atividade.

Os critérios que utilizamos para classificar os dados referentes às atividades de Não-Movimento foram os momentos em que as crianças tiveram que ficar presas a determinada situação, quietas e caladas, a pedido da professora.

Em muitos momentos, na instituição pesquisada, constatamos o grande empenho das professoras em fazer com que as crianças permanecessem sentadas ou paradas, sem produzir muito barulho. Elas obedeciam às professoras, por pouco tempo, e, depois, tentavam romper o imobilismo imposto de várias maneiras, como, por exemplo, não dormindo na hora determinada pela professora, levantando da cadeira na hora da refeição, etc.

Essa necessidade de movimento na criança entra em conflito com as exigências das atividades que a professora propõe. O controle dos movimentos para a realização das atividades é uma aprendizagem que leva tempo. A criança pequena utiliza-se, principalmente, de gestos para se 
expressar e "a redução da motricidade exterior e o ajustamento progressivo do movimento ao mundo físico está ligada também à possibilidade de controle voluntário sobre o ato motor" (GALVÃO, 2000, p. 75). Esse processo é gradativo e lento e depende não apenas do desenvolvimento das crianças, mas, principalmente, do tipo de intervenção educativa que as professoras realizam, fundamentalmente ajudando-as a controlar suas ações, incentivando-as a conhecer o corpo, as possibilidades de realizar movimentos que incrementem habilidades de expressão, concentração, observação, relacionamento com outras crianças e com adultos, entre outras importantes habilidades para a vida em sociedade.

Portanto, as atividades propostas pelas professoras devem ser variadas e desenvolvidas de forma a sempre instigar a criança a aprender algo novo ou, ainda, ir em busca do conhecimento. Sobre isso, Mukhina (1996, p. 179-180) sugere as "tarefas de estudo" como ferramenta que responde à curiosidade da criança e ao seu interesse em conhecer, nas quais o conteúdo da aprendizagem é o principal.

A aprendizagem do pré-escolar é de grande importância para que ele adquira uma formação inicial com vistas ao estudo escolar. Ensinar à criança os elementos que constituem a atividade escolar significa despertar nela o interesse por conhecer e prepará-la para aprender. (...)

Todas as crianças mostram interesse por matemática, língua ou ciências naturais, com a condição de que não recebam dados isolados, mas um sistema de conhecimentos que lhes permita compreender as principais relações entre os fenômenos que constituem a realidade. Quando as crianças assimilam essas leis elas demonstram enorme interesse por saber como essas leis gerais se manifestam em cada caso concreto; é dessa forma que compreendem que os estudos são o caminho para incríveis descobertas. (MUKHINA, 1996, p. 179-180)

Instigar o aprender na criança deve ser mais importante do que mantê-la quieta e em silêncio para ouvir. As educadoras têm a tarefa de mediar o conhecimento, e não de limitar ou restringir as atividades, em práticas mecânicas e sem sentido. $\mathrm{O}$ conhecimento não está diretamente relacionado ao Não-Movimento, mas, sim, a como ele é proporcionado às crianças pelas educadoras.

As professoras parecem relacionar a habilidade de atenção com o Não-Movimento, ou seja, para que a criança aprenda, existe a ideia de 
que ela deva, necessariamente, estar sentada olhando para a professora e qualquer movimento fora disso pode ser um sinal de desatenção, culminando em uma repreensão. Vejamos no episódio seguinte:

O brinquedo tênis (crianças de 2 a 3 anos)

As criancas estavam brincando com algumas bolinhas de argila dentro da sala de aula. Elas ficavam sentadas nas cadeiras. Não podiam se levantar porque a professora pedin que fosse assim. Havia, nesse grupo, uma criança que estava utiliz̧ando o próprio tênis como brinquedo, colocando as bolinhas dentro dele. Quando a professora viu a criança brincando, tirou o tênis das mãos dela e colocou-o no pé.

Parece haver uma intensa e cansativa luta contra o NãoMovimento por parte das crianças que são ativas, ansiosas por brincar, pular, gritar, conversar, cantar, etc. A professora parece querer contê-las, tentando, na maioria das vezes, fazer com que fiquem quietas, de preferência caladas, realizando as atividades de uma única maneira, estabelecida pela professora, que perde a chance de conhecer o pensamento e a brincadeira da criança no momento em que retira o tênis com que estava brincando, impedindo-a de continuar a testar, analisar, comparar, etc., habilidades importantes para o desenvolvimento.

As professoras têm grande desgaste em fazer com que as crianças fiquem quietas e caladas e, ao mesmo tempo, isso acarreta um prejuízo para a criança, pois a creche passa a ter o significado de um lugar onde ela deve conter-se sempre, ficar em silêncio, obedecer sem questionar e, no qual suas ideias, seus gostos, suas opiniões e reflexões não podem ser considerados. As crianças deixam de ter oportunidades de aprender novos conhecimentos de maneira prazerosa, como podemos observar no seguinte episódio:

A longa espera pelos pais (crianças de 2 a 3 anos)

Terminando o jantar, as crianças voltam para a sala para aguardar os pais. As professoras entregam as chupetas e pedem para que todas fiquem sentadas, encostadas no paredão (nome dado pelas professoras). As professoras ficam sentadas, cada uma em uma extremidade, vigiando as crianças. Essa é a hora de esperar a chegada dos pais, que começa aproximadamente às $16 \mathrm{~h}$ e termina às $17 \mathrm{~h}$. As criancas se movimentam, tentando sair da posição encostada na parede, mas as professoras voltam a pedir para que não se levantem. Uma das professoras estava com uma bola no colo e, ao jogá-la para cima, cain em frente de uma criança, que a pegou para brincar. Imediatamente, a professora tirou-a da criança e guardou-a.

Quando as crianças saíam do paredão, uma das professoras diz̨ia que iria contar até três 
para que encostassem novamente na parede. As crianças obedeciam, contrariadas e aborrecidas com a situação.

Este episódio revela a pobreza de interação e mediação da professora com as crianças. Para estas, qual o significado de ficarem encostadas na parede enquanto a professora tem uma bola nas mãos? Nesse momento de espera, mais uma vez, as crianças têm de se conter e obedecer às ordens da professora, que não aparentou nenhuma preocupação em oferecer qualquer atividade ou brinquedos enquanto as crianças aguardavam a chegada dos pais.

As professoras poderiam deixar as crianças brincando no parque ou oferecer brinquedos para que brincassem livremente, mas parece que a preocupação é controlá-las com atividades paradas. Esperar encostadas na parede é algo que parece representar esse domínio das professoras sobre as crianças.

Não podemos desconsiderar, neste episódio, o fato de as professoras de creche terem jornada diária de trabalho muito longa, o que pode justificar o cansaço ao final do dia e a necessidade de controlar as crianças. Entretanto, a forma de controle que utilizam é mais estafante do que se as deixassem livres para brincar neste longo tempo de espera dos pais. Mesmo que as crianças permanecessem em sala para aguardar a chegada deles, as professoras poderiam oferecer um espaço com diferentes objetos, cantos com roupas, brinquedos, livros, etc., com mais possibilidades de interação e movimentação com os ambientes e com os objetos, desenvolvendo inúmeras aprendizagens. Sobre isso Galvão (1996) aponta que:

No nosso entender, apropriar-se da influência do espaço sobre a dinâmica das interações significa concebê-lo como organizador da atividade do grupo, visando o favorecimento da atividade autônoma de seus elementos. Ocupar a sala com objetos que funcionem como sugestão para a atividade instrumental ou expressiva nos parece o ponto principal. Livro, brinquedos, jogos de regra, jogos de construção ou até mesmo cartazes com o registro de situações vividas ou temas estudados pelo grupo são algumas possibilidades. Entre o controle total e a ausência de direção por parte da professora, pode situar-se a regência exercida pelo espaço e seus objetos, parâmetro exterior que auxilia o controle autônomo do comportamento. (GALVÃO, 1996, p. 45-46)

Nos momentos em que as crianças têm oportunidade de brincar livremente, ainda é evidenciado o controle das professoras sobre seus movimentos, conforme relatamos a seguir: 
Escorregador (crianças de 2 a 3 anos)

Uma criança estava tentando subir na escada do escorregador, que é um pouco grande, $e$, por isso, estava com certa dificuldade. A professora, ao vê-la naquela situação, deu-lhe a mão, dizendo-lhe para que descesse da escada porque poderia cair. Ajudou a criança a sair, incentivando-a a desistir da ação.

Outra crianca estava esperando a sua vez, ficou observando e, depois de tentar subir o primeiro degrau, acabou desistindo também.

Essa é uma situação em que a professora incentiva o NãoMovimento, alegando que a criança pode se machucar. Parece que as professoras observam apenas o fato das crianças poderem se machucar e não vislumbram as possibilidades de ampliação do repertório de movimentos das crianças, que é muito importante para que elas conheçam o próprio corpo, seus limites e possibilidades, enfrentem desafios, etc.

Filgueiras (1998) encontra situação semelhante em sua pesquisa e apresenta da seguinte maneira:

Sob os olhares preocupados das professoras, os meninos escalavam o "morro" e escorregavam. Embaixo, havia uma região cimentada. As professoras restringiam a brincadeira para evitar que as crianças rolassem e batessem a cabeça, outra justificativa era a possibilidade de encontrar cacos de vidro ou insetos. Outra vez nos deparamos com o fato que recursos e limitações dependem da leitura dos atores sociais, ou seja, dos recursos simbólicos. Para um professor de educação física entusiasmado o talude significaria um recurso para propor atividades de escalar. (FILGUEIRAS, 1998, p. 162)

As professoras têm muito medo de que as crianças se machuquem e, por isso, as impedem de realizar determinados movi-mentos que consideram perigosos. Entretanto, nessas situações, se soubessem realizar as mediações de forma a dar suporte a atividades de brincadeiras, essa preocupação não seria empecilho para as aprendizagens das crianças. Isso é trabalhar na zona de desenvolvimento próximo, pois o que elas aprendem com ajuda do outro ganhará autonomia mais tarde (VIGOTSKI, 2001).

\section{CONSIDERAC̣ÕES FINAIS}

O propósito desta pesquisa foi identificar e analisar o trabalho com as atividades de Movimento desenvolvidas pelas profissionais de Educação Infantil na rotina diária da instituição pesquisada, com a finalidade de conhecer de que maneira elas promovem tais atividades. 
As atividades de Movimento para crianças pequenas são de fundamental importância para o seu desenvolvimento, tanto as atividades dirigidas, previamente planejadas, com objetivos claros, quanto a liberdade de movimentos na creche.

As professoras da creche têm experiência de trabalho com as crianças, mas falta-lhes o conhecimento de como trabalhar atividades educativas, como as de Movimento. Também é muito forte a ideia de manter as crianças quietas, incentivando o Não-Movimento. Parece haver a ideia de que o aprendizado dá-se a partir do controle sobre as crianças. O NãoMovimento, ou seja, a concepção que as educadoras têm de manter as crianças quietas e caladas, poderia ser discutido de maneira mais ampla, pois revela como as profissionais vêem a educação das crianças pequenas. É necessário (in)formá-las sobre o desenvolvimento da criança pequena, de modo que haja um encadeamento da sua prática com os conhecimentos sobre a criança, considerando suas características e instigando suas potencialidades.

A creche deve ser vista como o lugar onde se cuida e se educa as crianças. Entretanto, não deve ser concebida numa visão escolástica, com tudo o que a escola tem de nefasto e massificante.

O conflito ocorre quando se constata a falta de preparação das professoras para realizar atividades diversas, utilizando vários recursos que proporcionem, além dos cuidados, a educação às crianças.

Para que as professoras realizem seu trabalho, é importante que aprendam mais sobre sua função na Educação Infantil, que investiguem quais os recursos disponíveis e de que forma eles podem ser utilizados, quais os objetivos das atividades realizadas, assim como observem se são adequadas à faixa etária das crianças. Enfim, as educadoras necessitam ter momentos de reflexão sobre sua prática.

Um problema nos trabalhos desenvolvidos com crianças de 0 a 6 anos é a especificidade, que muitas vezes não é levada em consideração. A particularidade em desenvolver um trabalho com crianças pequenas exige formação abrangente e pormenorizada nas questões referentes à Educação Infantil.

O papel das profissionais que atuam na Educação Infantil é de extrema importância, pois elas têm de responder às exigências das crianças pequenas, sem cair no extremo assistencialista ou escolarizante.

Nesse momento, é fundamental que as profissionais percebam a importância de seu trabalho, agora como professoras, e que o desen- 
volvimento de atividades variadas com as crianças poderá lhes proporcionar um aprendizado significativo. Conscientes de seu papel, a busca de uma formação apropriada pode trazer muitos benefícios a elas e, principalmente, à vida das crianças.

Assim, é fundamental que as professoras tenham formação (inicial e continuada) específica para a Educação Infantil, de forma a contribuir para o trabalho com crianças pequenas, refletindo sempre sobre sua prática, de modo a produzir melhorias no trabalho, garantindo mais qualidade na Educação Infantil.

\section{REFERÊNCIAS}

BRASIL. Ministério da Educação e do Desporto. Secretaria de Educação Fundamental. Subsidios para Credenciamento e Funcionamento de Instituições de Educação Infantil, volume I. Brasília, Maio de 1998.

DUARTE, Newton. Vigotski e o "aprender a aprender": crítica às apropriações neoliberais e pós-modernas da teoria vigotskiana. 2 ed. rev. e ampl. Campinas, SPL Autores Associados, 2001. (Coleção educação contemporânea)

FILGUEIRAS, Isabel Porto. Espaços lúdicos ao ar livre na Educação Infantil. Dissertação de Mestrado apresentada à Faculdade de Educação da Universidade de São Paulo - USP (Área de concentração: Didática. Área temática: Psicologia e Educação), São Paulo, 1998. GALVÃO, Izabel. Henri Wallon. Uma concepção dialética do desenvolvimento infantil. 7 Ed. Petrópolis: Vozes, 2000.

GALVÃO, Izabel. A Questão do Movimento no cotidiano de uma pré-escola. In: Cadernos de Pesquisa, São Paulo, n. 98, p. 37 -49, ago. 1996.

IZA, Dijnane Fernanda Vedovatto. Quietas e caladas: Reflexões sobre as atividades de Movimento com crianças na Educação Infantil. Dissertação de Mestrado apresentada no Programa de Pós-Graduação em Educação da Universidade Federal de São Carlos UFSCar, 2003.

MELLO, Maria Aparecida. A atividade mediadora nos processos colaborativos de educaşão continuada de professores: Educação Infantil e Educação Física. Tese de Doutorado apresentada no Programa de Pós-Graduação em Educação da Universidade Federal de São Carlos - UFSCar, 2001.

MUKHINA, Valeria. Psicologia da idade pré-escolar. São Paulo: Martins Fontes, 1996.

VIGOTSKI, L. S. A construção do pensamento e da linguagem. São Paulo: Martins Fontes, 2001.

\section{NOTAS}

${ }^{1}$ Pesquisa de mestrado financiada pela Capes.

${ }^{2}$ Projeto: Diagnóstico das Creches do Município de São Carlos, financiado pela FAPESP 
, Processo n. 99/11608-0. (p. 1). Coordenadora Prof Dr $^{\mathrm{a}}$ Anete Abramowicz (UFSCar), Pesquisadoras Prof ${ }^{a}$ Dr $^{\mathrm{a}}$ Itacy Salgado Basso (UFSCar), Prof ${ }^{\mathrm{a}}$ Dr $^{\mathrm{a}}$ Maria Aparecida Melo (UFSCar), Prof. Dr. Admir Basso (EESC/USP); mestrandas: Dijnane F. Vedovatto Iza, Isabel Cristina de Jesus Brandão, doutoranda Maria Inês Crnkovic Octaviani.

${ }^{3}$ O Professor Paulo Bezerra, que traduziu o livro A Construção do Pensamento e da Linguagem, de Vigotski, justifica o termo zona de Desenvolvimento Imediato como: "a própria noção implícita no conceito vigotskiano de que, no desempenho do aluno que resolve problemas sem a mediação do professor, pode-se aferir incontinenti o nível de seu desenvolvimento mental imediato, fator de mensuração da dinâmica do seu desenvolvimento intelectual e do aproveitamento da aprendizagem" (Prólogo do tradutor, p. XI). Por outro lado, o Prof. Newton Duarte (2001), no prefácio de seu livro $V$ igostki e o Aprender a Aprender, argumenta que o tradutor se equivocou quando se refere ao conceito de Vigotski e faz as seguintes considerações: “(...) o Professor Paulo Bezerra interpreta que o conceito de zona de desenvolvimento próximo (ou imediato) focalizaria processos que a criança realiza sozinha, sem ajuda do professor, isto é, o tradutor confunde a zona de desenvolvimento próximo (ou imediato) com o nível de desenvolvimento atual. (...) Mesmo assim não posso deixar de enfatizar que, ao contrário do que entende o professor Paulo Bezerra, a zona de desenvolvimento próximo é constituída por aquilo que a criança, num determinado momento, não faz sozinha, mas o faz com a ajuda de outros, inclusive e principalmente do professor. É por isso que para Vigotski o único bom ensino é o que atua no âmbito da zona de desenvolvimento próximo. Aquilo que hoje a criança faz sozinha, mas no passado só fazia com ajuda, já foi interiorizado e foi incorporado ao nível de desenvolvimento atual".

${ }^{4}$ Informação obtida na Secretaria Municipal da Promoção e Bem-Estar Social.

${ }^{5}$ Dados fornecidos pela Secretaria Municipal de Educação e Cultura, referentes a março de 2002 .

${ }^{6}$ Este documento, produzido pela Secretaria de Educação Fundamental, sob coordenação de dirigentes do MEC, estabelece critérios para o credenciamento e o funcionamento de instituições de Educação Infantil.

Recebido: $17 / 11 / 2008$

Aprovado: 23/06/2009

Contato:

Rua Bernardino Fernandes Nunes, 1401

Cidade Jardim

São Carlos - SP

CEP 13566-490 